\title{
Pregnancy outcome with hepatitis E infection
}

\author{
Niranjan M. Mayadeo, Sachi N. Shah* \\ Department of Obstetrics and Gynecology, Seth G. S. Medical College and KEM Hospital, Mumbai, Maharashtra, \\ India
}

Received: 28 October 2018

Accepted: 13 December 2018

*Correspondence:

Dr. Sachi N. Shah,

E-mail: sachi.shah2@gmail.com

Copyright: (c) the author(s), publisher and licensee Medip Academy. This is an open-access article distributed under the terms of the Creative Commons Attribution Non-Commercial License, which permits unrestricted non-commercial use, distribution, and reproduction in any medium, provided the original work is properly cited.

\begin{abstract}
Background: Hepatitis E is usually a self-limited viral infection in men and non-pregnant women, but during pregnancy it is associated with high maternal and perinatal mortality. This needs to be studied for early diagnosis and better management.

Methods: The study commenced after the approval of Institutional Ethics Committee. This was a retrospective cum prospective observational study conducted in the Department of Obstetrics and Gynaecology and Department of Medical Intensive Care Unit in present tertiary care hospital between February 2012 and July 2017. An analysis of 120 cases was made over a period of five years.

Results: In this study the incidence of pregnant patients with hepatitis E was 3.09 per 1000 deliveries. It was found that majority of the patients which were diagnosed with hepatitis E were young and belonged to the age group of 21 25 years. Most of the affected patients were primigravida with increasing severity of the disease in their third trimester. The maternal morbidity was $51 \%$ with a mortality rate of $20 \%$. The percentage of still birth was $25.64 \%$ with increased incidence of preterm deliveries and poor perinatal outcome.

Conclusions: Early diagnosis and rapid management of the complications such as correction of abnormal coagulation and supportive management is the best treatment available at present. ICU admission and with strict maternal and foetal monitoring can help improve the outcome and thereby reducing the maternal and perinatal mortality.
\end{abstract}

Keywords: Hepatitis E, Maternal mortality, Perinatal mortality, Severe acute maternal morbidity, Viral hepatitis

\section{INTRODUCTION}

Acute viral hepatitis is an infection which predominantly affects the liver but can also lead to multiorgan failure. It is usually self-limited liver disease with a serum aspartate aminotransferase elevation of at least five-fold or clinical jaundice or both. ${ }^{1}$ Most of the cases of acute viral hepatitis are caused by one of five viral agents: hepatitis A virus (HAV), hepatitis B virus (HBV), hepatitis C virus (HCV), hepatitis D virus (HDV), and hepatitis E virus (HEV).

Hepatitis E infection is found to be a major cause of viral hepatitis all over the world. According the WHO review in the year 2017, there are approximately 20 million hepatitis E infections yearly, and 3.3 million symptomatic cases. Approximately 70,000 deaths per year have been attributed to $\mathrm{HEV}$ genotypes 1 and 2 and the estimated mortality is about $3.3 \%$. Case-fatality rates in highly endemic areas have ranged from $0.5 \%$ to $4 \%$ in hospitalbased data and $0.07 \%$ to $0.6 \%$ in population surveys during outbreaks. ${ }^{2}$ Hepatitis $\mathrm{E}$ is usually self-limited in men and non-pregnant women, but during pregnancy it is associated with high maternal mortality. ${ }^{3}$ Malnutrition superimposed on the normal demands of pregnancy and inversion of $\mathrm{T}$ and $\mathrm{B}$ lymphocytes in early pregnancy have been postulated to be the contributing factors for high level of incidence and complications. 
In pregnancy because of lower immune status, there is increased risk for viral replication which leads to higher case fatality rate among the pregnant women as compared to the general population.

Studies show that during outbreaks of waterborne hepatitis E in India and Asia the case-fatality rate was 1$2 \%$ in general population and up to $10-20 \%$ in pregnant women. Mortality rates among pregnant women, especially those infected in the third trimester, have ranged between $15 \%$ and $25 \%$, much higher that men and non-pregnant women. ${ }^{4}$

It has been reported that a significant proportion of pregnant women with acute hepatitis E progress to acute liver failure with a short pre-encephalopathy period, rapid development of cerebral oedema and high occurrence of disseminated intravascular coagulation. ${ }^{5}$ Hepatitis $\mathrm{E}$ in pregnancy is also associated with high rates of spontaneous abortion, intrauterine death, and preterm labour.

Prematurity in newborns and fulminant hepatic failure in mothers are major cause of poor fetomaternal outcome in acute hepatitis E with pregnancy. ${ }^{6}$ Hence authors have taken up this study for finding out ways for a better maternal and foetal outcome.

\section{METHODS}

The study commenced after the approval of Institutional Ethics Committee. This was a single centre observational study. A retro prospective analysis of hospital record of all obstetric cases with hepatitis E admitted in department of obstetrics and gynecology and medical intensive care unit at a tertiary care hospital was done over a period of five years.

\section{Inclusion criteria}

- All pregnant women admitted in present tertiary care centre with blood laboratory test showing positive titres only for active hepatitis E (IgM Hep-E) in the current pregnancy in their antenatal period or up to 42 days post-delivery were included in the study.

\section{Exclusion criteria}

- Pregnant women with laboratory tests showing positive titre for other viral type of Hepatitis or with any other cause of jaundice were excluded.

The retrospective analysis of hospital record of all cases with hepatitis E admitted in Department of Obstetrics and Gynecology and medical intensive care unit at a Tertiary care hospital was done and details were noted down in data record form. There was no patient interaction involved. Cases were seen from hospital records and wavier of consent was taken.
Data was collected from history and case records for these cases. In the prospective part of the study data of the patients who were newly diagnosed with Hepatitis E, their informed consent was taken and case history, investigations and maternal and fetal outcome were recorded. Since it was an observational study, findings were noted in the case record form. A comparison was done considering various demographic and medical parameters such as age of the patient, parity, gestational age, delivery mode, admission in critical care unit, presenting symptoms, complications and the perinatal outcome. Results were compared with percentage calculations.

\section{RESULTS}

\section{Incidence}

In this study total 120 cases of hepatitis $\mathrm{E}$ were observed. During the study period there were total 38817 deliveries in the tertiary care centre, and the incidence calculated was 3.09 per 1000 deliveries.

\section{Maternal parameters}

Age

According to Table 1 the maximum percentage of patients affected belonged to the age group of 21 to 25 years which was $47.52 \%$ of the total number of patients, followed by the age group between 26 to 30 years which contributed $41.66 \%$.

Table 1: Age groups of patients diagnosed as hepatitis E positive.

\begin{tabular}{|l|l|l|}
\hline Age & No. of cases & Percentage \\
\hline$<20$ & 2 & 1.66 \\
\hline $20-25$ & 57 & 47.52 \\
\hline $26-30$ & 50 & 41.66 \\
\hline$>30$ & 11 & 9.16 \\
\hline Total & 120 & 100 \\
\hline
\end{tabular}

Out of total 120 cases found majority were diagnosed to be hepatitis E positive in their third trimester, while very few were infected in the first and the second trimester. Analyzing this it shows that patients are more affected in their third trimester.

Table 2: Distribution according to the trimester of pregnancy.

\begin{tabular}{|l|l|l|}
$\begin{array}{l}\text { Duration of pregnancy } \\
\text { (gestational age in weeks) }\end{array}$ & $\begin{array}{l}\text { No. of } \\
\text { cases }\end{array}$ & Percentage \\
\hline $1^{\text {st }}$ trimester (up to 12weeks) & 2 & 1.67 \\
\hline $2^{\text {nd }}$ trimester (13-27weeks) & 15 & 12.50 \\
\hline $3^{\text {rd }}$ trimester (28 and above) & 103 & 85.83 \\
\hline Total & 120 & 100 \\
\hline
\end{tabular}




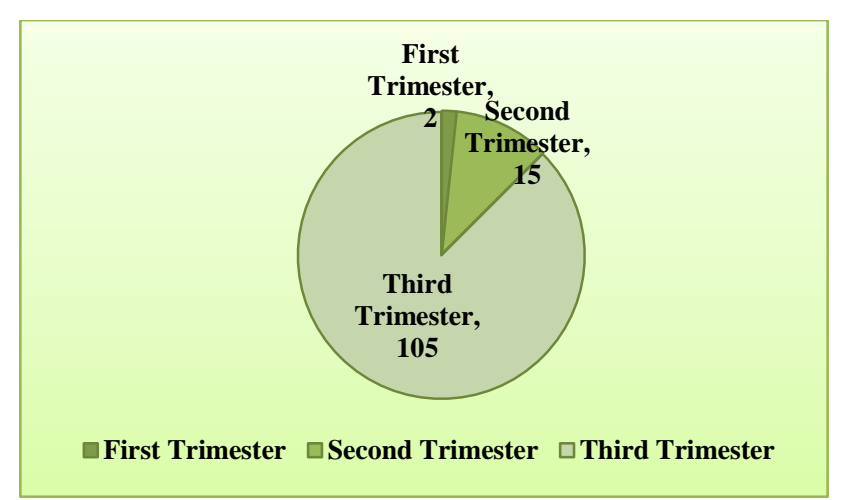

Figure 1: Distribution according to the gestational age.

\section{Clinical presentation}

The most common presenting symptom was jaundice i.e. either yellowish discoloration of skin or sclera or dark urine. Almost $92.5 \%$ of the affected individuals had jaundice.

Table 3: Clinical presentation on admission.

\begin{tabular}{|l|l|}
\hline $\begin{array}{l}\text { Clinical presentation at time of } \\
\text { admission }\end{array}$ & $\begin{array}{l}\text { No. of } \\
\text { cases }\end{array}$ \\
\hline Fever & 50 \\
\hline Loss of appetite & 10 \\
\hline Nausea/ vomiting & 25 \\
\hline Myalgia/ arthralgia & 3 \\
\hline Jaundice & 111 \\
\hline Pruritis & 5 \\
\hline Diarrhoea & 7 \\
\hline Altered sensorium & 15 \\
\hline Others & 4 \\
\hline
\end{tabular}

The second most common complaint was fever seen in about $41.6 \%$ of the patients, followed by nausea and vomiting. Pictorial description of the presenting symptoms is given in Figure 2.

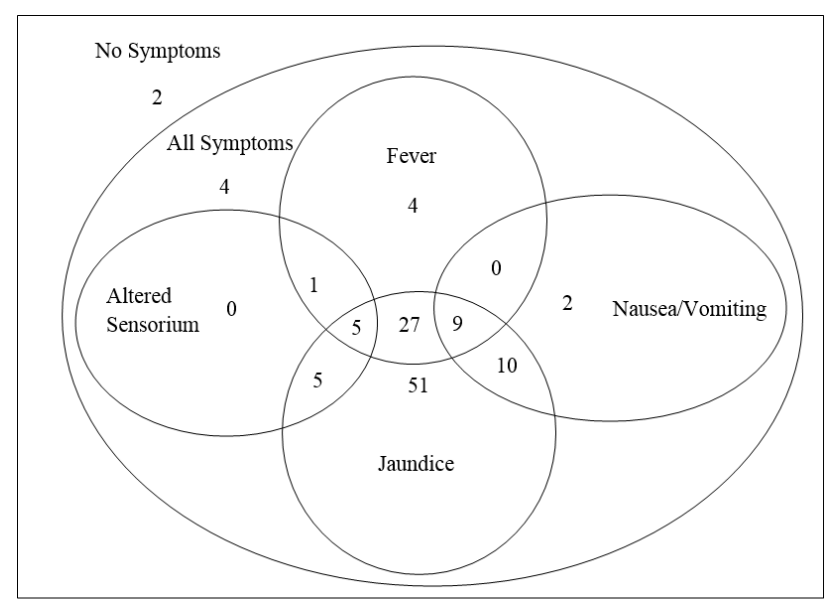

Figure 2: Presenting symptoms.

\section{Onset of labour}

According to available data $77.5 \%$ of the patients went into spontaneous labour, while $16.67 \%$ had to be induced. Among the remaining patients two had spontaneous abortion in their first trimester, one patient underwent an elective lower segment caesarean section in view of previous two lower segment caesarean sections, three patients died undelivered, while one patient was postnatal whose details regarding labour were not available.

Table 5: Onset of labour.

\begin{tabular}{|l|l|}
\hline Labour & No of cases \\
\hline Spontaneous & 93 \\
\hline Induced & 20 \\
\hline
\end{tabular}

There were total 120 cases out of which 115 delivered, 3 patients died undelivered and 2 patients had spontaneous abortion. Out of total 115 patients delivered 100 patients delivered vaginally and 15 underwent lower segment caesarean section. Vaginal delivery is preferred over operative interventions in these patients because of increased risk of bleeding and morbidity due to abnormal coagulation.

Table 6: Mode of delivery.

\begin{tabular}{|l|l|}
\hline Mode of delivery & No. of cases \\
\hline Vaginal delivery & 100 \\
\hline Caesarean section & 15 \\
\hline Spontaneous Abortion & 2 \\
\hline Undelivered & 3 \\
\hline
\end{tabular}

\section{Maternal outcome}

Maternal outcome has been analyzed as number of morbid cases, total number of patients requiring admission into intensive care setups and number of mortalities.

\section{Maternal morbidity}

Table 7: Morbid conditions.

\begin{tabular}{|l|l|}
\hline Maternal morbidity & Frequency \\
\hline Hepatic encephalopathy & 34 \\
\hline Deranged coagulation profile & 61 \\
\hline Post-partum haemorrhage & 6 \\
\hline Renal failure & 3 \\
\hline
\end{tabular}

There were total 62 cases with morbid condition. Out of these 62 patients, 38 survived and 24 patients died. Out of total 62 patients, 61 patients had abnormal coagulation profile, 34 patients had hepatic encephalopathy, 6 patients post-partum haemorrhage and 3 patients had hepatorenal involvement. Pictorial representation of the same is given in Figure 3. 


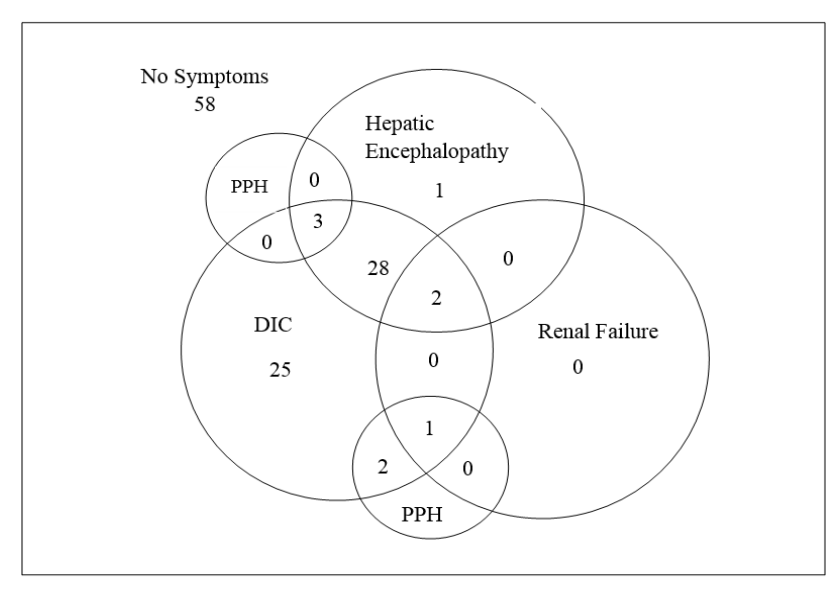

Figure 3: Complications.

\section{Need for intensive care unit admission}

A total of 79 patients out of 120 required admission in medical intensive care unit which is $66 \%$ of the total number of patients with hepatitis $\mathrm{E}$.

\section{Maternal mortality}

Out of total 120 patients there were total 24 maternal mortalities. The percentage of mortality was approximately $20 \%$.

Comparative analysis of the investigative parameters between the survivors and the non-survivors

Table 8: Maternal survival.

\begin{tabular}{|l|l|l|}
\hline Investigation & Survivor & Non-survivor \\
\hline Total number of patients & 96 & 24 \\
\hline Median haemoglobin $(\mathrm{mg} \%)$ & 11 & 8.5 \\
\hline Median TLC $\left(\mathrm{mm}^{3}\right)$ & 13000 & 18350 \\
\hline Median platelet $(\mathrm{lacs})$ & 2.15 & 1.8 \\
\hline Median of SGOT (IU) & 358.26 & 1520.50 \\
\hline Median of SGOT(IU) & 268 & 1115 \\
\hline Median total bilirubin (mg/dl) & 7.60 & 13.1 \\
\hline Median INR & 1.26 & 4.1 \\
\hline
\end{tabular}

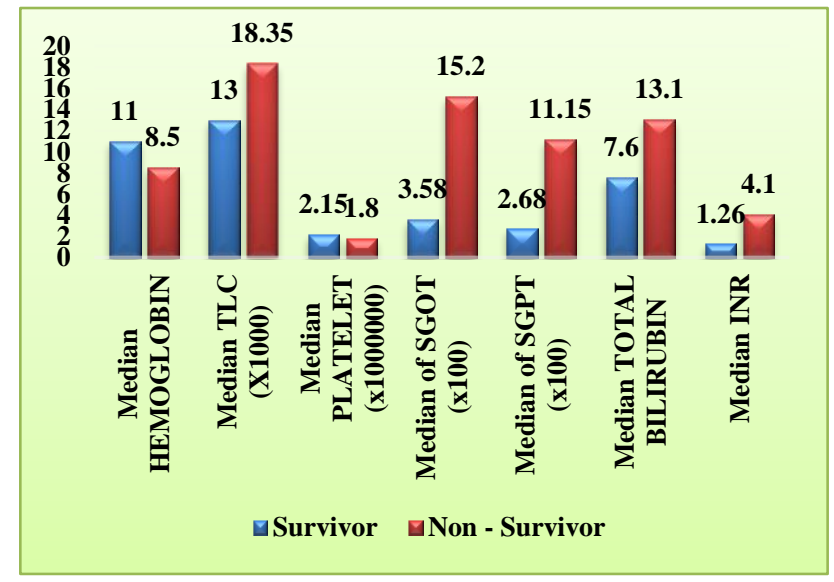

Figure 4: Maternal outcome.
This comparative analysis shows that poor maternal outcomes were seen with fall in the haemoglobin levels and platelet count, and with rise in the total leukocyte count, SGOT, SGPT, serum bilirubin levels, and INR.

\section{Foetal outcome}

There were total 117 deliveries, out of which there were total 85 live births, 30 still birth and 2 patients had spontaneous abortion. Out of the 85 live births there were total 46 full term deliveries and 39 preterm deliveries.

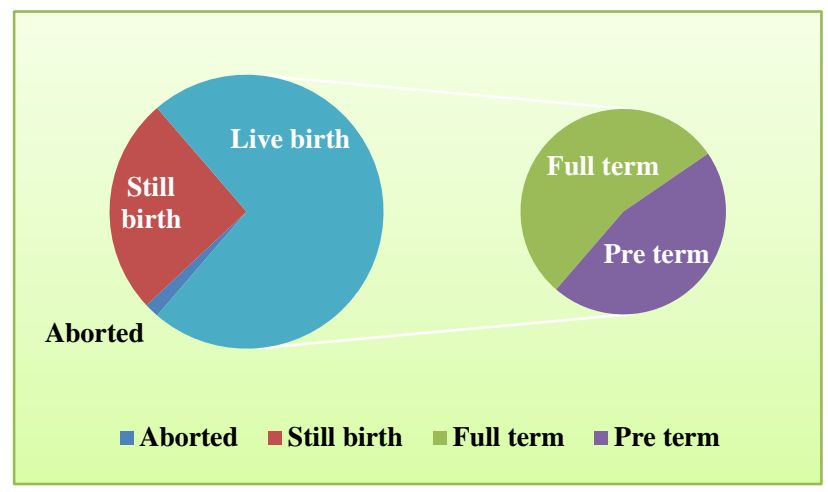

Figure 5: Foetal outcome.

Neonatal Intensive Care Unit admission and neonatal mortality

There were total 85 live births out of which 25 newborns required NICU admissions. Out of these 25 admissions, 19 babies were admitted for low birth weight and prematurity, while 5 had perinatal asphyxia, and one was admitted for evaluation of congenital cardiac anomaly. Out of these two infants one died because of prematurity and asphyxia, and the other because of extremely low birth weight and extreme prematurity.

\section{DISCUSSION}

\section{Incidence}

The incidence calculated in the present study is 3.09 per 1000 deliveries which are similar to the incidence in the study by Patra et al which is 3.95 per 1000 deliveries and lower than Kumar et al which are 8.6 per 1000 deliveries. ${ }^{7,8}$

Age

Most of the affected patients in this study were between the ages of 21-30 years. Among them the most common age group affected is 21 to 25 years which constitutes $47.5 \%$ of the total affected individuals. These results are comparable with various other studies published which are shown in Table 9.

This result may suggest that younger age might have a greater predilection for hepatitis E infection. 
Table 9: Majority of population affected.

\begin{tabular}{|c|c|c|}
\hline Study & $\begin{array}{l}\text { Majority of } \\
\text { population affected }\end{array}$ & Percentage \\
\hline Present study & $21-25$ years & 47.5 \\
\hline Mishra S et $\mathrm{al}^{9}$ & 21-24 years & 41.90 \\
\hline Adjei $\mathrm{A}$ et $\mathrm{al}^{10}$ & 21-25 years & 46.15 \\
\hline
\end{tabular}

\section{Gestational age}

The mean gestational age affected in the present study is 32.5 weeks of gestation with maximum number of patients in their third trimester. Comparison of this study with various other studies have been shown in the table below which shows higher number of pregnant women affected in the third trimester.

Table 10: Trimester distribution.

\begin{tabular}{|c|c|c|}
\hline Study & $\begin{array}{l}\text { Total pregnant } \\
\text { hepatitis } \mathbf{E} \\
\text { patients studied }\end{array}$ & $\begin{array}{l}\text { Percentage of } \\
\text { patients in } \\
\text { third trimester }\end{array}$ \\
\hline Present study & 120 & 87.50 \\
\hline Patra et $\mathrm{al}^{7}$ & 132 & 88 \\
\hline Adjei et al $^{10}$ & 157 & 75.79 \\
\hline Badrakiya et al ${ }^{11}$ & 39 & 79.5 \\
\hline Shinde et al ${ }^{12}$ & 52 & 63.4 \\
\hline
\end{tabular}

\section{Clinical presentation at the time of admission}

In present study $92.5 \%$ of the patients presented with jaundice as their chief complaint, followed by fever which was seen in $41.6 \%$ of the affected cases, while $20.83 \%$ of patients had nausea/vomiting and $12.5 \%$ presented with altered sensorium. Yellowish discoloration of urine or sclera was observed in $91.42 \%$ of patients in the study published by Mishra et al conducted in the year $2016 .^{9}$

According to Shinde et al almost all of cases in their study had nausea/vomiting, $86.5 \%$ had jaundice, $58 \%$ had fever, while $21.1 \%$ had hepatic encephalopathy. ${ }^{12}$ Hence according to various studies that have been analyzed most of the affected patients have clinical jaundice and other common complaints are nausea or vomiting, fever while more critical patients have hepatic encephalopathy.

\section{Type of labour}

In present study total 117 patients delivered out which most of the patients had a spontaneous labour and some underwent induction of labour. These results are consistent with the study conducted by Patra et al in which $41 \%$ of patients were in active labour on admission and $44 \%$ of patients went into active labour after admission. $^{7}$ Therefore total $85 \%$ of the patients went into spontaneous labour. In the study by Badrakiya et al it was found that out of 39 patients studied with hepatitis E, $82 \%$ had spontaneous onset of labour. ${ }^{11}$

\section{Mode of delivery}

Out of total 117 patients delivered nearly all patients delivered vaginally and only 15 patients underwent lower segment caesarean section. Majority of patients with hepatitis E had a spontaneous onset of labour, progressed well and delivered vaginally. In present study $87.1 \%$ patients had a vaginal delivery as compared to only $12.9 \%$ of lower segment caesarean section.

Similar results have been seen in a study conducted by Kumar et al at King George Medical College, Lucknow wherein $90.63 \%$ patients delivered vaginally and $9.37 \%$ underwent lower segment caesarean section. ${ }^{8}$ Also in the study by Badrakiya et al, $82 \%$ of pregnant patients with Hepatitis E had vaginal delivery while the percentage of caesarean section was $15.4 \% .{ }^{11}$ The inference from this analysis is that patients with hepatitis E go more often into spontaneous labour and deliver vaginally and less operative intervention is required. Moreover, authors have encountered situation where even though the pregnancy and foetus is precious, counselling for no operative intervention needs to be done from patient in maternal interest due to abnormal coagulation and deranged liver function tests. These abnormalities do increase the risk of poor maternal outcome if any operative intervention is done.

\section{Maternal morbidity}

Authors have analyzed maternal morbidity in terms of major medical complications occurring due to hepatitis $\mathrm{E}$ in pregnancy which is coagulation defect, hepatic encephalopathy, post-partum haemorrhage and hepatorenal derangements. In this study total 120 patients with hepatitis E were studied out of which nearly half of the patients had abnormal coagulation.

This result is slightly higher than the result obtained from Kumar et al in which $31.2 \%$ had abnormal coagulation; however, it is lower than the study published by Patra et al in which $79 \%$ of cases had coagulopathies due to Hepatitis E.,8 The results of this present study are consistent with the studies published by Mishra et al and Badrakiya et al in which the percentage of patients with abnormal coagulation were $54.29 \%$ and $60 \%$ respectively. ${ }^{9,11}$

Percentage of patients complicated with hepatic encephalopathy in this study was $28.3 \%$ which is found to be slightly higher to the studies published by Mishra et al, Kumar et al, and Badrakiya et al with their respective results as $20.95 \%, 21.8 \%$ and $15.4 \% .^{8,9,11}$

Postpartum haemorrhage as a complication reported by Patra et al was $14 \%$ while according to present study it was $5 \%$ which is similar to as reported by Badrakiya et al. ${ }^{7,11}$ Hepatorenal complications were seen in very few patients which compares with Badrakiya et al where it was $2.6 \%$. $^{11}$ 


\section{Maternal mortality}

In this present study there were total 24 maternal mortalities. Therefore, the percentage of maternal mortality in the present study is $20 \%$. This result has been compared with various other similar studies. Patra et al shows it maternal mortality was approximately $15-20 \%{ }^{7}$ A paper published by Badrakiya et al shows that maternal mortality rate among the pregnant women with hepatitis E infection was $20.5 \%$ while Benita et al analyzed that maternal mortality rate in their study was $30-45 \% .{ }^{9}$ Thus, hepatitis $\mathrm{E}$ infection is an important cause of maternal mortality.

\section{Comparison of investigative parameters amongst the survivor group and the non-survivor group}

In the present study it is found that the maternal outcomes were poorer with higher levels of SGOT, SGPT, S. Bilirubin, INR and total leukocyte count, and with falling levels of Haemoglobin and Platelet counts.

These results are consistent with the study published in Turkish Journal of Obstetrics and Gynaecology by Kumar et al. ${ }^{8}$ The average bilirubin level among the survivor group was $6 \mathrm{mg} / \mathrm{dl}$ and non-survivor group was $15 \mathrm{mg} / \mathrm{dl}$ which is consistent with the present study where it is $7.6 \mathrm{mg} / \mathrm{dl}$ and $13 \mathrm{mg} / \mathrm{dl}$. The levels of SGOT and SGPT are also comparable where it was 313 IU and 332 IU in the survivors and 1240 IU and 1670 IU respectively amongst the non survivors in the study by Kumar et al to the results in the present study where the average levels of SGOT and SGPT in the patients discharged were 268 IU and 358 IU respectively and among the patients who died was $1115 \mathrm{IU}$ and $1520 \mathrm{IU}^{8}{ }^{8}$ The mean platelet count has also been compared in the both studies. In the study by Kumar et al it is 1.5 lacs in the survivors while 0.85 lacs in the non survivors while in this study it is 2.15 lacs in the survivor group and 1.8 among the non-survivor group. ${ }^{8}$ This data of present study has also been compared with the study published by Sahai $\mathrm{S}$ et al. ${ }^{13}$ In this study the average haemoglobin among the survivors was $7.6 \mathrm{mg} / \mathrm{dl}$ and non survivors was $7 \mathrm{mg} / \mathrm{dl}$. In the study by Sahai $\mathrm{S}$ et al the average bilirubin, SGOT, SGPT and INR reported were $11.57 \mathrm{mg} \%$, $305.46 \mathrm{IU}, 457.48 \mathrm{IU}, 1.12$ amongst the survivors and $16.08 \mathrm{mg} \%, 316.60 \mathrm{IU}, 310.69$ IU, 2.40 amongst the non-survivors which were found to be similar with present study. ${ }^{13}$

\section{Foetal outcome}

In this recent study, out of 117 deliveries there were 85 live births, 30 still births and 2 spontaneous abortions. Among them nearly half were full term deliveries and remaining were preterm deliveries. The percentage of still birth was $25 \%$ and that of spontaneous abortion was only $1.72 \%$. The neonatal intensive care unit admission was approximately $30 \%$, in which majority were because of low birth weight and prematurity. The neonatal mortality rate among the babies admitted in NICU was $12 \%$, and the perinatal mortality rate was $28 \%$. Kumar et al reports live birth rate of $56 \%$ and still birth rate of $45 \% .^{8}$ In the same study one third patients had term deliveries while the remaining majority were preterm deliveries. An article written by Patra et al says that in their study there were $21 \%$ live births and $54 \%$ still births. ${ }^{7}$ Out of which there were $90 \%$ preterm deliveries with $17 \%$ neonatal death. The rate of spontaneous abortion was $8 \%$ which is slightly higher than the present study. Similar study by Badrakiya et al shows $66 \%$ live births and $34 \%$ of still births. ${ }^{11}$ There were total $25 \%$ full term deliveries and $72 \%$ preterm deliveries with neonatal intensive care unit admission rate of almost $70 \%$. This data from various studies shows that there is higher incidence of still birth which ranges from one third to almost half of the deliveries with higher incidences of preterm deliveries ranging from nearly half to almost all the deliveries. The rate of spontaneous abortion is not increased probably due to lesser number of patients affected in their first trimester compared to the number of patients in their third trimester.

The limitations of this study were that actual number of the pregnant cases affected with hepatitis $\mathrm{E}$ is not obtained since this study is limited to a single tertiary care centre and only high-risk patient got transferred to the centre for further management.

\section{CONCLUSION}

The incidence of pregnant patients with hepatitis $\mathrm{E}$ in the present study is 3.09 per 1000 deliveries. It is found that nearly half of the patients which are diagnosed with hepatitis E were young and belonged to the age group of 21-25 years.

Maximum numbers of the patients when diagnosed were in their third trimester of pregnancy, showing that patients are more vulnerable for hepatitis $\mathrm{E}$ infection in their latter part of pregnancy. The most common presenting complaint of the patients in this study was jaundice or yellowish discoloration of sclera and urine which was found in almost $90 \%$ of the cases, followed by fever, nausea/vomiting and altered sensorium.

Almost $80 \%$ of the cases went into spontaneous labour, either before or after admission and rest had to be induced mainly in view of intrauterine foetal demise or preterm premature rupture of membranes. Majority of the patients delivered vaginally and only $13 \%$ of the patients had to be operated. In this study approximately $51 \%$ of the patients were morbid out of which $38 \%$ could not survive.

The maternal mortality rate in the present study is found to be $20 \%$. Higher mortality was found in patients with hepatic encephalopathy and disseminated intravascular coagulation. The maternal outcome was poorer with rising levels of SGOT, SGPT, bilirubin, INR. There were higher percentage of still birth and increased incidence of 
preterm deliveries with poor perinatal outcome in patients suffering from hepatitis $\mathrm{E}$, especially in their third trimester.

Early diagnosis and rapid management of the complications such as correction of abnormal coagulation and supportive management is the only treatment available at present. ICU admission and with strict maternal and foetal monitoring can help improve the outcome.

\section{ACKNOWLEDGMENTS}

Authors would like to acknowledge Dr. Madhva Prasad for the help in improvement of manuscript.

Funding: No funding sources

Conflict of interest: None declared

Ethical approval: The study was approved by the Institutional Ethics Committee

\section{REFERENCES}

1. Hepatic, gallbladder, and pancreatic disorders. In: Cunningham G, Leveno KJ, Bloom SL, Hauth JC, Rouse DW, Spong CY, eds. Williams Obstetrics. $23^{\text {rd }}$ ed. McGraw Hill: NewYork; 2010:1063.

2. Smedile A, Carcil, Verme G. Influence of delta infection on severity of hepatitis B. Lancet 1982;2:945-7.

3. Goumba, C, Yandoko-nakoune, E, Komas, N. A fatal case of acute hepatitis E among pregnant women, Central African Republic. BMC Research Notes. 2010;3(103):1-4.

4. Khuroo MS, Teli MR, Skidmore S, Sofi MA. Incidence and severity of viral hepatitis in pregnancy. Am J Med. 1981;70:252-5.

5. Khuroo MS, Kamili S. Aetiology, clinical course and outcome of sporadic acute viral hepatitis in pregnancy. J Viral Hepat. 2003;10:61-9.
6. Sultana, R, Humayun, S. Fetomaternal outcome in acute hepatitis E. J Coll Physicians Surg Pak. 2014;24(2):127-30.

7. PatraS, Kumar A, Trivedi S. Maternal and fetal outcomes in pregnant women with acute hepatitis E virus infection. Ann Intl Med. 2007;147:28-33.

8. Kumar N, Das V, Agarwal A. Fetomaternal outcomes in pregnant women with hepatitis $\mathrm{E}$ infection; still an important fetomaternal killer with an unresolved mystery of increased virulence in pregnancy. Turkish J Obstet Gynecol. 2017;14:10613.

9. Mishra S, Jha RK, Thakur R, Tiwari S. Study of maternal and prenatal outcome in pregnant women with acute hepatitis $\mathrm{E}$ viral infection. Int $\mathrm{J}$ Reprod Contracept Obstet Gynecol. 2017;5(7):2300-3.

10. Adjei AA, Tettey Y, Aviyase JT, Adu-Gyamfi C, Obed S, Mingle JA, et al. Hepatitis E virus infection is highly prevalent among pregnant women in Accra, Ghana. Virol J. 2009;6(1):108.

11. Badrakiya GL, Chauhan DV, Jethwa DK, Badrakiya SG. Hepatitis E virus in pregnancy with fetomaternal outcome-A prospective study. IOSR J Dent Med Sci. 2015;14(8):25-8.

12. Shinde N, Patil T, Deshpande A, Gulhane R, Patil M, Bansod Y. Clinical profile, maternal and fetal outcomes of acute hepatitis e in pregnancy. Ann Med Health Sci Res. 2014;4(Suppl 2):S133-9.

13. Sahai S, Mishra V, Ganga D, Jatav OP. Viral hepatitis in pregnancy-a study of its effect on maternal and foetal outcome. J Assoc Physicians India. 2015;63:28-33.

Cite this article as: Mayadeo NM, Shah SN.

Pregnancy outcome with hepatitis E infection. Int J Reprod Contracept Obstet Gynecol 2019;8:467-73. 